\title{
СИСТЕМА УПРАВЛІННЯ РЕЖИМОМ ДОТРИМАННЯ РІВНОВАГИ АНТРОПОМОРФНИМ КРОКУЮЧИМ AПAPATOM
}

\begin{abstract}
Анотація: У роботі запропоновано розв'язання задачі управління режимом дотримання рівноваги антропоморфного крокуючого апарата на довільній твердій поверхній на основі застосування принципу відслідковування переміщення точки центру мас апарата та сили реакції опорної поверхні.

Ключові слова: Антропоморфний крокуючий апарат, дотримання нестійкої рівноваги, ієрархічна система управління, Hardware in the loop, отримальне правління рівновагою.
\end{abstract}

\section{Вступ}

Побудова антропоморфних крокуючих апаратів (АКА) залишається однією з актуальних задач сьогодення, вирішення якої матиме значний економічний та соціальний ефект завдяки потенціально більшій прохідності ї у порівнянні з будь-якими іншими апаратами. Проте технічна реалізація АКА ускладнена, насамперед, відсутністю систем управління (СУ), якіб забезпечували їх рівновагу та враховували вплив навколишнього середовища $[1,2,4-7]$.

У даній роботі запропоновано розв'язання задачі управління режимом дотримання рівноваги АКА у статичних фразах руху довільною твердою поверхнею на основі застосування принципу відслідковування залежності переміщення точки центру мас апарата від сили реакції опорної поверхні [4-7].

Огляд принципів дії існуючих СУ дотримання рівноваги

Найбільший вклад у вивчення двоногого людиноподібного руху внесли Chow C.K., Jackobson D.H., Hill J.C., Mc-Gee, Pei та Muybridge E.

Так, у працях Chow C.K. i Jackobson D.H. [9,2] забезпечення рівноваги АКА здійснюеться шляхом застосування другої теореми Ляпунова. При цьому апарат розглядається як механічна система маятникового типу, визначена у двох площинах. Рух корпусу апарата розглядається як рух твердого тіла з тьома ступенями свободи і описуеться через коеріцієнти кутів Ейлера: $\theta, \psi, \varphi$, які утворюють інерційну систему відліку. Зокрема, кут $\theta$ визначається поворотом корпуса навколо вертикальної осі. Взявши точку О за центр відліку системи координат, яка задана рівняннями:

$$
\begin{aligned}
& x_{c}=f(t)+\rho \sin (\theta) \cos (\psi), \\
& y_{c}=h(t)+\rho \cos (\theta) \sin (p s i), \\
& z_{c}=h(t)+\rho \sin (\psi) .
\end{aligned}
$$

(c) М.М. Ткач, Д.О. Гуменний, 2014 
кінетична енергія апарата може бути визначена так:

$$
T_{\text {nocmyn }}=1 / 2 M\left(I_{0} \omega_{1}^{2}+I_{2} \omega_{2}^{2}+I_{0} \omega_{3}^{2}\right)
$$

де $\omega_{i}, i=[1 . .3]$ - кутове прискорення відносно осей $O x, O y, O z-$ відповідно, $I_{0}, I_{2}$ - головні моменти інерції у відповідних осях. При цьому, якщо використати рівняння основних моментів інерції:

$$
\begin{aligned}
& \omega_{1}=\dot{\psi} \cos (\varphi)+\dot{\theta} \sin (\varphi) \cos (\psi) \\
& \omega_{2}=\dot{\varphi}-\dot{\theta} \sin (\psi) \\
& \omega_{3}=\dot{\psi} \sin (\varphi)-\dot{\theta} \cos (\varphi) \cos (\psi)
\end{aligned}
$$

то можна отримати рівняння для кінетичної та потенціальної енергії. Тоді значення моменів в шарірах по відношенню до головних осей, опишуться так:

$$
d / d t \cdot d T / d q_{i}-d T / d q_{i}+d V / d q_{i}=M_{i},
$$

де $M_{i}, q_{i}$ - моменти та кути між головними осями - відповідно.

Зважаючи на те, що кути власного обертання корпуса навколо вертикальної осі малі, у порівнянні з кутами $\theta, \psi$ то їх вилучення дало можливість авторам роботи звести модель дотримання рівноваги до системи рівнянь четвертого порядку.

Таким чином, з точки зору теоретичного підходу, роботи Chow C.K. i Jackobson D.H. є прикладом того, як загальна теорема стійкості Ляпунова може бути використана для вивчення стійкості антропоморфних систем. Однак, суттєві спрощення механічної моделі і переоцінка реальних фрізичних можливостей управління системою, нівелюють практичну цінність роботи. У загальному випадку, такий метод управління апаратом не передбачає можливість його переміщення по поверхні. Натомість управління рівновагою здійснюеться лише за рахунок переміщення корпуса, що складно уявити на практиці.

Робота Hill J.C. [10,2], яка присвячена управлінню постановчої пози апарата, у значній мірі відрізніеться від роботи Chow C.K. та Jackobson D.H. Автор описуе модель апарата, який складаеться з семи ланок і враховує сили та моменти, що діють на ці ланки. Для опису динаміки системи застосоване рівняння Лагранжа другого роду:

$$
\frac{d}{d t} \frac{d T}{d q_{i}}-\frac{d T}{d q_{i}}+\frac{d V}{d q_{i}}=Q_{i}, i=[1 . . n],
$$

де $q_{i}$ - і-та узагальна координата; $\dot{q}_{i}$ - похідна по часу від узагальненої координати; $V$ - загальна потенціальна енергія системи; $T$ загальна кінетична енергія системи; $Q$ - і-та узагальнена сила, що утворена узагальненими моментами та опорною реакцією.

Наведене вище рівняння зводиться до нелінійної моделі виду: 


$$
\dot{A} \dot{z}=\left(\dot{B} z^{2}\right)+C f(z)+V+Q,
$$

де $\ddot{z}, \dot{z}, z, f(z), V, Q$ визначені дев'ятикомпонентними векторами. Визначення узагальнених сил даної моделі здійснюється у два етапи: на першому, реакції у шарнірах прирівнюються нулю та опис моделі здійснюється лише з моментів сил у шарнірах; на другому, визначаються реакції у шарнірах, при відповідних моментах у щарнірах рівних нулю. Потреба у двоетапному визначенні узагальнених сил пов'язана з взаємовпливом означених параметрів.

На основі отриманої нелінійної динамічної моделі, представленої у вигляді векторного диференційного рівняння

$$
\frac{d V}{d t}=\frac{d V}{d \theta} \dot{\theta}+\frac{d V}{d \psi} \dot{\psi}+\frac{d V}{d \dot{\theta}} \ddot{\theta}+\frac{d V}{d \dot{\psi}} \ddot{\psi}
$$

і побудовано модель руху апарата.

Хоча в цій роботі використовувалась неповна нелінійна модель, проте результати дослідження підтверджують можливість їі практичного застосування. Хоча дана модель і має високу деталізацію, однак обрана невдало, так яким чином незрозуміло, як результати ії роботи можуть розповсюджуватися на реальні технічні апарати з двома кінцівками. Питання яку пов'язане з реакціями опор, не вирішене, так як очевидно, що вираження цих реакцій через координати та їх добутки з застосуванням постійних коефіцієнтів складно реалізувати. У роботі також не вирішена проблема зв'язку між внутрішніми та абсолютними координатами.

У роботі Mc-Geе та Реi розглянуто апарат, який має чотири кінцівки, вага кожної з яких нескінченно мала. у порівнянні з вагою корпуса. Нівелювання ваги кінцівок призводить до лінеаризації формалізованої моделі апарата та його СУ. При цьому, основний акцент в архітектурі СУ робиться на людино-машинний принцип управління. Такі особливості архітектурного рішення дозволили суттєво спростити загальну будову зворотного зв'язку та СУ в цілому.

У роботі Майбіджа [11,2] відмічено, що деякі тварини ставлять кінцівки так, щоб стопа знаходилася майже під центром ваги корпуса. Такий рух можна апроксимувати, прийнявши кожну пару кінцівок тварини як одну кінцівку людиноподібного апарата. При цьому, задача дотримання рівноваги зводиться до математичної задачі перевернутого маятника.

Таким чином, система управління рівновагою розглядає в якості об'єкта управління механічну систему, визначену у тримірному просторі, який складатиметься із семи або більше ланок, що мають лінійні розміри та маси. На кінематичні пари ланок накладатимуться обмеження кутів та моментів. Для збереження рівноваги апарата використовуеться апріорне джерело інформації про його 
взаємодію з опорною поверхнею. Застосування теореми Ляпунова у якості критерію рівноваги ускладнено у зв'язку з потребую формалізації апарата як одноланкової системи маятникового типу.

Проведений аналіз публікацій показуе, що існуючі системи управління дотримання рівноваги крокуючих апаратів орієнтовані на ідеалізовані, апріорі-задані параметри апарату та опорної поверхні його руху. Таким чиному, практичне застосування існуючих СУ має низку проблем, що пов'язані, на сам перед, з їх адаптивними властивостями, потребою управління об'єктом який описується диференійним рівнянням високого порядку та здійснення управління в режимі реального часу.

Для вирішення даних проблем управління рівновагою АКА пропонуеться здійснювати ієрархічною СУ з елементами адаптивності, що базуеться на особливосях взаемодії апарата з опорною поверхнею, а вирішення диференійних рівнянь викокого порядку здійснювати шляхом часткових похідних та послідовного рішення складових рівняння на кожному з рівнів ієрархії представленої СУ.

\section{Узагальнена структура ієрархічної $1 \mathrm{CУ}$ дотриманням рівноваги АКА}

Як відомо, розподіл сили реакції опорної поверхні на стопи АКА відображає положення точки проекції центру мас апарата в залежності від кутів нахилу та екстремумів висот на поверхні [4-6]. Це дає можливість, на основі отриманих даних щодо розподілу сили реакції опори, виконати корекційне управління положенням ланок АКА для уникнення падіння та дотримання стану, близького до рівноваги.

Зважаючи на конструктивні особливості АКА, до складу якого входить низка ланок, пов'язаних шарнірами з відповідними актуаторами та сенсорами поточного кута й кутової швидкості, на них накладені відповідні кутові обмеження (рис. 1). Крім того, положення точки центру мас АКА залежить від положення кожної з його ланок, що пов'язано з їх масами (для спрощення зосереджуються у точках) та довжинами, а також для дотримання рівноваги AКА накладається обмеження на можливість проковзування його опори по ОП.

Тоді, для корекції стану рівноваги АКА, за приципом моніторингу розподілу сили реакції опори, необхідно розв'язати такі задачі:

- визначити критерії дотримання рівноваги АКА, втрати рівноваги, наближення до втрати рівноваги тощо, на основі яких побудувати відповідний регулятор забезпечення рівноваги АКА;

- на основі методів вирішення зворотної задачі динаміки розробити блок перерахунку кутів кінцівок АКА, який дозволить 


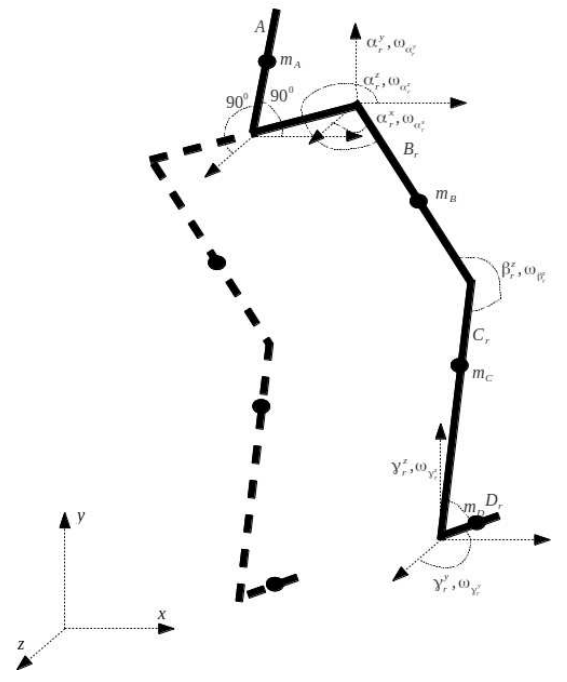

Рис. 1 - Загальна система зв'язків семиланкового АКА у тримірному просторі: А - корпус; В - бедро; С - гомілка; D - стопа; $\alpha_{r}^{x}, \alpha_{r}^{y}, \alpha_{r}^{z}, \alpha_{r}^{x}$, $\alpha_{r}^{y}, \alpha_{r}^{z}, \alpha_{r}^{x}, \alpha_{r}^{y}, \alpha_{r}^{z}$ - кути пульпового шарніру правої кінцівки у площинах $X, Y, Z$ - відповідно; $\beta_{r}^{z}$ - кут у колінному шарнірі правої кінцівки; $\gamma_{r}^{z}, \gamma_{r}^{y}-$ кути правох гомілки у площинах $Y, Z$; між ланками апарата; $m_{A}, m_{B}, m_{C}$, $m_{D}$ - маси ланок корпусу, бедра, гомілки та стопи; $\omega_{a_{r}}^{x}, \omega_{a_{r}}^{y}, \omega_{a_{r}}^{z}$ - моменти у пульповому шарнірі правої кінцівки; $\omega_{\beta_{r}}^{z}-$ момент у колінному шарнірі правої кінцівки; $\omega_{\gamma_{r}}^{y}, \omega_{\gamma_{r}}^{z}$ - моменти у гомілковому шарнірі правої кінцівки. Назви ланок, кутів та моменті для лівої кінцівки визначаються подібно до правої

визначити відхилення кожного кута апарату від бажаного для дотримання його рівноваги.

- синтезувати регулятор кута, який забезпечить переміщення точки центру мас АКА у положення, визначене як оптимальне дотримання рівноваги АКА за однією зі степеней свободи;

- синтезувати додатковий регулятор, який враховуе інерціальну складову кінцівок АКА.

Перераховані регулятори об'єднуються у загальну систему управління режимом дотримання рівноваги АКА, структурна схема якої зображена на рисунку 2 . Принцип роботи даної схеми полягає в наступному: з тактильної сенсорної матриці зчитуються дані розподілу сили реакції опорної поверхні, що передаються до блоку регулювання рівноваги АКА у вигляді двомірного масиву, сумарне значення елементів якого відповідає силі натиску АКА на опор- 
ну поверхню. Блок регулювання рівноваги АКА, на основі отриманих даних про розподіл сили реакції опорної поверхні, визначає поточне положення ТПЦМ та оптимальне за критерієм мінімального відхилення від області рівноваги АКА. Дані про поточне та оптимальне положення ТПЦМ АКА з блоку регулювання рівноваги АКА передаються до блоку перерахунку кутів кінцівок АКА у вигляді двох пар координат ТПЦМ на поверхні. У свою чергу, блок перерахунку кутів АКА складаеться з двох однакових блоків перерахунку кутів лівої та правої кінцівок, які виконують перехід до нових кутів кінцівок АКА з метою переміщення ТПЦМ до оптимального положення зі збереженням “комфортності" руху АКА та однозначістю позиції спільної точки обох кінцівок апарата. Нові кути у кінцівках АКА визначаються розв'язками зворотної задачі кінематики. Після отримання нових кутів кожен з них передається у відповідний блок регулювання кута. Блок регулювання кута складається з блоку перетворення кута та регулятора кута в шарнірі. Блок перетворення кута перевіряе входження нового кута в “коридор” допустимих значень та у випадку невходження переприсвоюе йому значення найближчого за величиною допустимого кута в шарнірі. Вихідне значення кута передається до регулятора кута в шарнірі. Також до регулятора надходить поточне його значення. На основі даних про новий та поточний кути обраховується кутова швидкість і прискорення в шарнірі. Диференційною передатною функціею третього порядку визначаєтся значення сили, яку потрібно прикласти в шарнірі для переходу від поточного кута до нового. Вихідне значення регулятора передається до актуатора. Зважаючи на індефірентність інерційної складової в управлінні АКА, що пов'язано зі взаємним впливом моментів інерції кожної ланки, паралельно до регулятора кута в шарнірі побудовано коригуючий регулятор кута. У випадку малого відхилення між новим та поточним кутами коригуючий регулятор формуе додатковий момент управління актуатором, спрямований на зменшення розбіжностей між кутами. Для формування додатковго моменту управління актуатором, до коригуючого регулятора надходять значення: нового кута, поточних кутів кінцівки, маси та лінійних розмірів ланок. Формування моменту відбувається за принципом адаптивного самонавчаючого методу Хебба. Значення поточного кута, що надходить до регуляторів управління кутами, отримуеться безпосереднім зчитуванням сенсорами з актуаторів АКА.

Блок перетворення кутів у кінцівках та блок регулювання кута мають класичні вирішення, тому не розглядатимуться у цій статі.

Блок регулювання кута

У відповідності до робіт [2,4-7,11], рівновага АКА буде дотримана, якщо точка проекції центру мас (ТПЦМ) АКА знаходитиметься у певному околі рівноваги, що сформований на основі проекції опор апарата на поверхню руху. Для випадку опису контуру опор АКА 


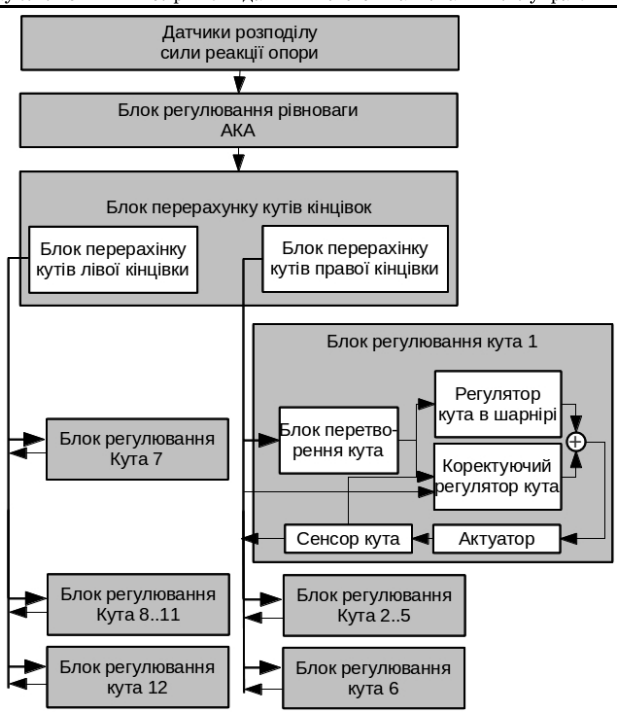

Рис. 2 - Загальна структурна схема СУ дотриманням рівноваги AKA

як лінійних функцій, умова дотримання рівноваги сформулюеться розв'язком задачі оптимізації:

$$
\begin{aligned}
& \max \left[\sum_{y=1}^{y=\text { border }_{l}^{y}} \sum_{x=1}^{x=\text { border }_{f}^{x}} \widehat{N}_{z}, x, y\right] \\
& f^{\text {foot }}\left(x_{i}, y_{j}, \widehat{N}_{z}\right) \leqslant \text { border }_{1} \\
& f^{\text {foot }}\left(x_{i}, y_{j}, \widehat{N_{z}}\right) \geqslant \text { border }_{2} \\
& f^{\text {foot }}\left(x_{i}, y_{j}, \widehat{N}_{z}\right) \geqslant \text { border }_{3} \\
& f^{\text {foot }}\left(x_{i}, y_{j}, \widehat{N_{z}}\right) \leqslant \text { border }_{4} \\
& i, j \in R
\end{aligned}
$$

де: border $[1 . .4]$ - границя опори стопи АКА зліва, справа, ззаду, спереду - відповідно (рис. 3$) ; f^{f o o t}([x, y, z])$ - лінійна функція, що описуе контур стопи у фронтальній чи латеральній площинах; $\operatorname{border}_{l(f)}^{x(y)}$ - граничне значення максимуму даних про розподіл сили реакції опори у площині $x$ або $y$; $\widehat{N_{x, y, z}}-$ значення сили реакції опори у точці; $x, y$ - відповідні координати точки, з якої здійснюється зчитування розподілу сили реакції опори; $z$ - значення зчитування сили реакції опори з точки, характеризованої координатами $x, y$.

Успішне синтезування блоку регулювання рівноваги АКА потребуе представлення формул задачі оптимізації 1 як механізму 


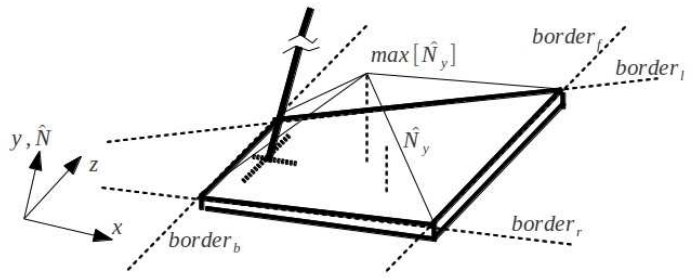

Рис. 3 - Критерій пошуку оптимального положення ТПЦМ на стопі AKA

опрацювання дійсної сили реакції опори на розглянутій стопі апарата. Тому перетворимо дані, отримані з датчиків сили реакції опори у фрункцію розподілу маси апарата за формулою 2 :

$$
\begin{aligned}
& M=\sum_{i=1}^{n} \sum_{j=1}^{m} N_{i, j} \cdot k ;[i=1 . . x, j . . y], k \in R \\
& M=m_{A}+2\left(m_{B}+m_{C}+m_{D}\right) \\
& m_{x, y}=N_{x, y} \cdot k
\end{aligned}
$$

де $N$ - зчитана з сенсорів натиску матриця розподілу сили реакції опори; $k$ - коефіцієнт перетворення сили натиску в точці на масу; $M$ - загальна маса AКА; $m_{A}, m_{B}, m_{C}, m_{D}$ - маси ланок AКА; $m_{x, y}$ маса, спроектована в точку на стопі з координатами $x, y$. Область прикладання маси до опорної поверхні, згідно з формулами (1), описуеться дотичною поверхнею стоп АКА до опорної поверхні. Границі дотичної поверхні змінюються у відповідності до фази руху, що зумовлено кутами в шарнірах АКА. Форма поточної дотичної поверхні визначається наявністю в кожній з їі точок сили реакції опори, яка відповідае умові (5) у межах зовнішнього контуру обох стоп апарата. Просторове положення стоп по відношенню до корпуса АКА визначається з координат точок їхнього підвісу до гомілок у рівняннях (3), константних розмірів стопи АКА, які задані в моделі, та дискретизованої матриці розподілу маси апарата, виведеної у рівняннях (5). Кути просторового положення стоп не впливають на розподіл сили реакції опори, що пов'язано з інваріантністю типів поверхні, тому не враховані у рівняннях (3-6).

$$
\begin{aligned}
& y_{0}^{r}=y_{A}^{r}+\left(L_{B}+L_{C}\right) \cos \left(\alpha_{r}^{x}\right) \\
& x_{0}^{r}=x_{A}^{r}+L_{B} \cos \left(\alpha_{r}^{z}\right)+L_{C} \cos \left(\beta_{r}^{z}\right) \\
& y_{0}^{l}=y_{A}^{l}+\left(L_{B}+L_{C}\right) \cos \left(\alpha_{l}^{x}\right) \\
& x_{0}^{l}=x_{A}^{l}+L_{B} \cos \left(\alpha_{l}^{z}\right)+L_{C} \cos \left(\beta_{l}^{z}\right)
\end{aligned}
$$

де $y_{0}^{r}, x_{0}^{r}, y_{0}^{l}, x_{0}^{l}$ - координати точок підвісу стоп до гомілок АКА; $L_{A}, L_{B}, L_{C},-$ константні довжини ланок; $x_{A}^{r}, y_{A}^{r}, x_{A}^{l}, y_{A}^{l}-$ координати точки підвісу бедер до корпуса; $\alpha_{r}^{x}, \alpha_{r}^{z}, \alpha_{l}^{x}, \alpha_{l}^{z}, \beta_{r}^{z}, \alpha_{l}^{z}-$ кути 
визначені в рисунку (1). Контур стоп АКА можна записати у виді функцій (4)

$$
\begin{aligned}
& x_{0}^{r} \cos \left(\alpha_{r}^{x}\right)+y_{0}^{r} \sin \left(\alpha_{r}^{x}\right)-\frac{w d t_{D}}{2}=0 \\
& x_{0}^{r} \cos \left(\alpha_{r}^{x}\right)+y_{0}^{r} \sin \left(\alpha_{r}^{x}\right)+\frac{w d t_{D}}{2}=0 \\
& x_{0}^{r} \cos \left(\alpha_{r}^{x}+90\right)+y_{0}^{r} \sin \left(\alpha_{r}^{x}+90\right)=0 \\
& x_{0}^{r} \cos \left(\alpha_{r}^{x}+90\right)+y_{0}^{r} \sin \left(\alpha_{r}^{x}+90\right)-l e n_{D}=0 \\
& x_{0}^{l} \cos \left(\alpha_{l}^{x}\right)+y_{0}^{l} \sin \left(\alpha_{l}^{x}\right)-\frac{w d t_{D}}{2}=0 \\
& x_{0}^{l} \cos \left(\alpha_{l}^{x}\right)+y_{0}^{l} \sin \left(\alpha_{l}^{x}\right)+\frac{w d t_{D}}{2}=0 \\
& x_{0}^{l} \cos \left(\alpha_{l}^{x}+90\right)+y_{0}^{l} \sin \left(\alpha_{l}^{x}+90\right)=0 \\
& x_{0}^{l} \cos \left(\alpha_{l}^{x}+90\right)+y_{0}^{l} \sin \left(\alpha_{l}^{x}+90\right)-l e n_{D}=0
\end{aligned}
$$

а перехід від координат точки на стопі до сили натиску на точку виконуеться фрормулами (5):

$$
\begin{aligned}
& N^{g}(x, y)=S_{n, m}, \\
& i \frac{\operatorname{len}_{D}}{k} \geqslant n \geqslant[i+1] \frac{\text { len }_{D}}{k} \\
& j \frac{w d t_{D}}{l} \geqslant m \geqslant[j+1] \frac{w d t_{D}}{l} \\
& i=[1 . . k-1], j=[1 . . l-1], g=[1,2]
\end{aligned}
$$

де $l e n_{D}, w d t_{D}$ - константні довжина та ширина стопи АКА; $k, l$ кількість датчиків натиску по осях $x$ та $y ; S_{n, m}-$ значення сили натиску, отримане з комірки сенсорної матриці, $g$ - ідентифікатор опори.

$$
\begin{aligned}
& N_{x, y}>\sigma \\
& \sigma \rightarrow 0
\end{aligned},
$$

Беручи до уваги залежність границь рівноваги AКА від фрази руху, визначимо фразу з умов $(4,6)$ :

$$
\begin{gathered}
{\left[f_{r}=1\right]} \\
x_{0}^{r} \cos \left(\alpha_{r}^{x}+90\right)+y_{0}^{r} \sin \left(\alpha_{r}^{x}+90\right)>x> \\
>x_{0}^{r} \cos \left(\alpha_{r}^{x}+90\right)+y_{0}^{r} \sin \left(\alpha_{r}^{x}+90\right)-l e n_{D} \wedge \\
\exists(x, y),\left([ N _ { x , y } > \sigma ] \wedge \left[x_{0}^{r} \cos \left(\alpha_{r}^{x}\right)+y_{0}^{r} \sin \left(\alpha_{r}^{x}\right)+\frac{w d t_{D}}{2}>y>\right.\right. \\
\left.\left.>x_{0}^{r} \cos \left(\alpha_{r}^{x}\right)+y_{0}^{r} \sin \left(\alpha_{r}^{x}\right)-\frac{w d t_{D}}{2}\right]\right) \\
{\left[f_{l}=2\right],} \\
x_{0}^{l} \cos \left(\alpha_{l}^{x}+90\right)+y_{0}^{l} \sin \left(\alpha_{l}^{x}+90\right)>x> \\
>x_{0}^{l} \cos \left(\alpha_{l}^{x}+90\right)+y_{0}^{l} \sin \left(\alpha_{l}^{x}+90\right)-l e n_{D} \\
\exists(x, y),\left([ N _ { x , y } > \sigma ] \wedge \left[\wedge x_{0}^{l} \cos \left(\alpha_{l}^{x}\right)+y_{0}^{l} \sin \left(\alpha_{l}^{x}\right)+\frac{w d t_{D}}{2}>y>\right.\right. \\
\left.\left.>x_{0}^{l} \cos \left(\alpha_{l}^{x}\right)+y_{0}^{l} \sin \left(\alpha_{l}^{x}\right)-\frac{w d t_{D}}{2}\right]\right) . \\
f_{l}+f_{r}=1
\end{gathered}
$$

де $f_{l}+f_{r}=1 . .3$ - класифікатор одноопорної та двоопорної фаз руху. У випадку одноопорної фази руху, коли $f_{l}+f_{r}<3$ крайні точки стопи, що формують контур області рівноваги АКА та на які діє сила реакції опори, визначається із рівнянь (7): 


$$
\begin{aligned}
& x_{1}=i, N_{g}(\min (i), j)>\sigma \\
& y_{1}=j, N_{g}(\min (i), j)>\sigma \\
& x_{2}=i, N_{g}(\max (i), j)>\sigma \\
& y_{2}=j, N_{g}(\max (i), j)>\sigma \\
& x_{3}=i, N_{g}(i, \min (j))>\sigma \\
& y_{3}=j, N_{g}(i, \min (j))>\sigma \\
& x_{4}=i, N_{g}(i, \max (j))>\sigma \\
& y_{4}=j, N_{g}(i, \max (j))>\sigma \\
& i=1 . . n, j=1 . . m
\end{aligned}
$$

де $n, m$ - розрядність сенсорної матриці стопи у площинах та $y-$ відповідно; $g$ - ідентифікатор кніцівки. Тоді прямі, побудовані через ці точки за принципом обходу контуру, сфромують дотичну поверхню на стопі. Прямі контуру рівноваги описані таким чином:

$$
\begin{aligned}
& \frac{y-y_{1}}{y_{2}-y_{1}}-\frac{x-x_{1}}{x_{2}-x_{1}}=0 \\
& \frac{y-y_{2}}{y_{3}-y_{2}}-\frac{x-x_{2}}{x_{3}-x_{2}}=0 \\
& \frac{y-y_{3}}{y_{4}-y_{3}}-\frac{x-x_{3}}{x_{4}-x_{3}}=0 \\
& \frac{y-y_{4}}{y_{1}-y_{4}}-\frac{x-x_{4}}{x_{1}-x_{4}}=0
\end{aligned}
$$

виражаємо рівняння прямих контуру через кутове положення у площині ута підставляємо його значення у відповідності до рис.1. Тоді, рівняння прямих контуру описується наступним чином:

$$
\begin{aligned}
& \operatorname{tg}\left(\alpha_{i}^{y}\right) x-x_{1}+y_{1}-y=0 \\
& \operatorname{tg}\left(\alpha_{i}^{y}\right)\left[x-x_{2}\right]+y_{2}-y=0 \\
& \operatorname{tg}\left(\alpha_{i}^{y}\right)\left[x-x_{3}\right]+y_{3}-y=0 \\
& \operatorname{tg}\left(\alpha_{i}^{y}\right)\left[x-x_{4}\right]+y_{4}-y=0
\end{aligned}
$$

Перевизначення координат точок до виду абсолютних координат ланки D здійснюеться з використанням формули (5). Подання прямих у системі координат, відносно точок підвісу опор, задано перетворенням над рівняннями прямих. 3 метою збереження наочності, ідентифікатори координат залишаються незмінними.Отримаємо:

$$
\begin{aligned}
& \text { border }_{1} \equiv \operatorname{tg}\left(\alpha_{i}^{y}\right)\left[x-x_{1}\right]+\left(y_{1}+\left[y_{0}^{i}-\frac{w d t_{D}}{2}\right]\right)-y=0 \\
& \text { border }_{2} \equiv \operatorname{tg}\left(\alpha_{i}^{y}\right)\left[x-x_{2}\right]+\left(y_{2}+\left[y_{0}^{i}-\frac{w d t_{D}}{2}\right]\right)-y=0 \\
& \text { border }_{3} \equiv \operatorname{tg}\left(\alpha_{i}^{y}\right)\left[x-x_{3}\right]+\left(y_{3}+\left[y_{0}^{i}-\frac{w d t_{D}}{2}\right]\right)-y=0 \\
& \text { border }_{4} \equiv \operatorname{tg}\left(\alpha_{i}^{y}\right)\left[x-x_{4}\right]+\left(y_{4}+\left[y_{0}^{i}-\frac{w d t_{D}}{2}\right]\right)-y=0 \\
& {[x, y] \in N} \\
& i=f_{r}+f_{l}
\end{aligned}
$$


де $w d t_{D}$ - ширина (по осі $y$ ) стопи АКА; $x_{0}^{i}, y_{0}^{i}$ - координати шарніра на стопі апарата, що визначені у рівняннях (3); $l, r$-ідентифікатори лівої та правої стоп; $f_{l}, f_{r}$-ідентифікатори наявності сили реакції опори, що визначені у рівнянні (6).

Для випадку двоопорної фрази руху, (коли $f_{l}+f_{r}=3$ ) граничні, точки побудови прямих повинні відповідати умовам (9):

$$
\begin{aligned}
& {\left[N_{l}(x, y)>\sigma, x=x_{0}^{l} \ldots\left[x_{0}^{l}+i\right]\right. \text {; }} \\
& \left.y=\left[y_{0}^{l}-1 / 2 w d t_{D}\right] \ldots\left[y_{0}^{l}+1 / 2 w d t_{D}\right]\right] \\
& x_{1}=\min (x) \Leftarrow y=\begin{array}{l}
{\left[N_{r}(x, y)>\sigma, x=x_{0}^{r} \ldots\left[x_{0}^{r}+i\right] ;\right.} \\
\left.\left[y_{0}^{l}-1 / 2 w d t_{D}\right] \ldots\left[y_{0}^{r}+1 / 2 w d t_{D}\right]\right]
\end{array} \\
& y_{1}=y,\left[N_{r}\left(x_{1}, y\right)>\sigma\right. \\
& \left.y=\left[y_{0}^{r}-1 / 2 w d t_{D}\right] \ldots\left[y_{0}^{r}+1 / 2 w d t_{D}\right]\right] \\
& \begin{aligned}
& {\left[N_{l}(x, y)>\sigma, x=x_{0}^{l} \ldots\left[x_{0}^{l}+i\right] ;\right.} \\
& {\left.\left[y_{0}^{l}-1 / 2 w d t_{D}\right] \ldots\left[y_{0}^{l}+1 / 2 w d t_{D}\right]\right] } \\
& {\left[N_{r}(x, y)>\sigma, x=x_{0}^{r} \ldots\left[x_{0}^{r}+i\right] ;\right.} \\
&\left.x_{2}=\max (x) \Leftarrow \quad\left[y_{0}^{l}-1 / 2 w d t_{D}\right] \ldots\left[y_{0}^{r}+1 / 2 w d t_{D}\right]\right]
\end{aligned} \\
& y_{2}=y,\left[N_{r}\left(x_{2}, y\right)>\sigma\right. \text {, } \\
& \left.y=\left[y_{0}^{r}-1 / 2 w d t_{D}\right] \ldots\left[y_{0}^{r}+1 / 2 w d t_{D}\right]\right] \\
& {\left[N_{l}(x, y)>\sigma, x=x_{0}^{r} \ldots\left[x_{0}^{r}+i\right]\right. \text {; }} \\
& \left.y=\left[y_{0}^{r}-1 / 2 w d t_{D}\right] \ldots\left[y_{0}^{r}+1 / 2 w d t_{D}\right]\right] \\
& y_{3}=\min (y) \Leftarrow y=\begin{array}{l}
{\left[N_{r}(x, y)>\sigma, x=x_{0}^{r} \ldots\left[x_{0}^{r}+i\right]\right.} \\
\left.\left[y_{0}^{r}-1 / 2 w d t_{D}\right] \ldots\left[y_{0}^{r}+1 / 2 w d t_{D}\right]\right]
\end{array} \\
& x_{3}=x,\left[N_{r}\left(x, y_{3}\right)>\sigma\right. \text {, } \\
& \left.y=\left[y_{0}^{r}-1 / 2 w d t_{D}\right] \ldots\left[y_{0}^{r}+1 / 2 w d t_{D}\right]\right] \\
& {\left[N_{l}(x, y)>\sigma, x=x_{0}^{r} \ldots\left[x_{0}^{r}+i\right]\right. \text {; }} \\
& \left.y=\left[y_{0}^{r}-1 / 2 w d t_{D}\right] \ldots\left[y_{0}^{r}+1 / 2 w d t_{D}\right]\right] \\
& y_{4}=\max (y) \Leftarrow y=\begin{array}{l}
{\left[N_{r}(x, y)>\sigma, x=x_{0}^{r} \ldots\left[x_{0}^{r}+i\right] ;\right.} \\
\left.\left[y_{0}^{r}-1 / 2 w d t_{D}\right] \ldots\left[y_{0}^{r}+1 / 2 w d t_{D}\right]\right]
\end{array} \\
& x_{4}=x,\left[N_{r}\left(x, y_{4}\right)>\sigma\right. \text {, } \\
& \left.y=\left[y_{0}^{r}-1 / 2 w d t_{D}\right] \ldots\left[y_{0}^{r}+1 / 2 w d t_{D}\right]\right]
\end{aligned}
$$

а контур області дотримання рівноваги визначатиметься прямими, сорормованими точками з рівнянь (9) і буде описаний рівнянням(8).

Тоді поточна позиція ТПЦМ АКА для одноопорної та двоопорної фаз руху визначатиметься із розв'язку умови (1) для системи обмежень $(8,10)$ з урахуванням критерію оптимальності з умови $(2)$. У загальному вигляді позиція ТПЦМ визначається методом Гоморі 3 наступної постановки задачі: 


$$
\begin{gathered}
\max \left[\sum_{r=1}^{k} N_{\left.x_{i}+\left(r^{2}-y^{2}\right), y_{j}+\left(r^{2}-x^{2}\right)\right]}\right] \\
\operatorname{tg}\left(\alpha_{i}^{y}\right)\left[x-x_{1}\right]+\left(y_{1}+\left[y_{0}^{i}-\frac{w d t_{D}}{2}\right]\right)-y \geqslant \sigma \\
\operatorname{tg}\left(\alpha_{i}^{y}\right)\left[x-x_{2}\right]+\left(y_{2}+\left[y_{0}^{i}-\frac{w d t_{D}}{2}\right]\right)-y \geqslant \sigma \\
\operatorname{tg}\left(\alpha_{i}^{y}\right)\left[x-x_{3}\right]+\left(y_{3}+\left[y_{0}^{i}-\frac{w d t_{D}}{2}\right]\right)-y \leqslant \sigma \\
\operatorname{tg}\left(\alpha_{i}^{y}\right)\left[x-x_{4}\right]+\left(y_{4}+\left[y_{0}^{i}-\frac{w d t_{D}}{2}\right]\right)-y \leqslant \sigma \\
{[x, y] \in N} \\
i=f_{r}+f_{l} \\
x_{i}, y_{j}, r \in N \geqslant 0 \\
x_{\text {rea }}^{\text {dof }}=x ; y_{\text {rea }}^{\text {dof }}=y
\end{gathered}
$$

На відміну від поточної ТПЦМ, оптимальне положення ТПЦМ визначається за критерієм усереднення розподілу маси АКА на всю поверхню стоп. Зауважуючи існування поточного розподілу сили реакції опори, задача пошуку оптимального положення ТПЦМ перетворюеться в задачу перерозподілу сили реакції опори. Ця задача може бути вирішеною при застосуванні угорського методу розв'язання задач лінійного програмування для випадку розподілу ресурсів. Так, початкова матриця розподілу складатиметься з елементів, що характеризуватимуть відносну завантаженість точки на стопі, у порівнянні зі всіма іншими ії точками. Завантаженість кожної з точок визначатиметься з чисельного значення кожного елемента матриці C:

$$
\begin{aligned}
C= & \left|\begin{array}{cccc}
c_{11} & c_{12} & \ldots & c_{1 i} \\
c_{21} & c_{22} & \ldots & c_{2 i} \\
\ldots & \ldots & \ldots & \ldots \\
c_{j 1} & c_{j 2} & \ldots & c_{j i}
\end{array}\right| ; i=1 . . k, j=1 . . l \\
\hat{c}_{i j} & =\left|s-N_{i j}\right| \\
& s=\frac{\sum_{i=1}^{k} \sum_{j=1}^{l} N_{i j}}{i j}
\end{aligned}
$$

Критерієм оптимального положення ТПЦМ є досягнення умови:

$$
C=\left|\begin{array}{cccc}
\hat{s}+\hat{\sigma} & \hat{s}+\hat{\sigma} & \ldots & \hat{s}+\hat{\sigma} \\
\hat{s}+\hat{\sigma} & \hat{s}+\hat{\sigma} & \ldots & \hat{s}+\hat{\sigma} \\
\ldots & \ldots & \ldots & \ldots \\
\hat{s}+\hat{\sigma} & \hat{s}+\hat{\sigma} & \ldots & \hat{s}+\hat{\sigma} \\
\hat{\sigma} \rightarrow 0 & &
\end{array}\right|
$$

яке виконається за умови переміщення ТПЦМ співвідношенням: 


$$
\begin{aligned}
& C=\left|\begin{array}{ccccc}
c_{11} & c_{12} & \ldots & c_{1 i} & A_{1} \\
c_{21} & c_{22} & \ldots & c_{2 i} & A_{2} \\
\ldots & \ldots & \ldots & \ldots & \ldots \\
c_{j 1} & c_{j 2} & \ldots & c_{j i} & A_{j} \\
B_{1} & B_{2} & \ldots & B_{i} &
\end{array}\right| \\
& A_{j}=\sum_{i=1}^{i=k} c_{i j} ; B_{i}=\sum_{j=1}^{j=l} c_{i j} \\
& x_{o p t}^{d o f}=x_{r e a}^{d o f}+\left[\frac{\max \left[A_{j}\right]-\min \left[A_{j}\right]}{\sum_{i=1}^{i=k} A_{j}}\right] k \\
& y_{\text {opt }}^{\text {dof }}=y_{\text {rea }}^{\text {dof }}+\left[\frac{\max \left[B_{i}\right]-\min \left[B_{i}\right]}{\sum_{j=1}^{j=k} B_{i}}\right] l \text {. }
\end{aligned}
$$

Вихідним значенням блоку регулювання рівноваги АКА $є$ координати поточної та оптимальної ТПЦМ, що передаються у вигляді вектора (12).

$$
y^{D O F}=\left[x_{\text {rea }}^{\text {dof }}, y_{\text {rea }}^{\text {dof }}, x_{o p t}^{\text {dof }}, y_{\text {opt }}^{\text {dof }}\right] .
$$

Для перерахунку кутів у шарнірах АКА, у відповідності до знайденого оптимального положення ТПЦМ, застосовано метод вирішення зворотної задачі кінематики, який реалізований у блоці перерахунку кутів кінцівок (рис. 2).

\section{Висновок}

Запропонована в роботі СУ має ієрархічну структуру і забезпечуе дотримання динамічної рівноваги АКА. Розроблена СУ базується на оптимальних методах детермінації положення рівноваги, розв'язанні зворотної задачі кінематики для розрахунку кутів між кінематичними парами апарата та здійснюе управління актуаторами в шарнірах AКА, застосовуючи для цього комплексний регулятор адаптивного характеру.

\section{Біблиографічний список}

1. Vukobratovic M., Borovac B. and Potkonjak V., Towards a unified understanding of basic notions and terms in humanoid robotics, Robotica 25 (2007) 87-101

2. Белецкий В.В. Двуногая ходьба: модельные задачи динамики и управления. - М.: Наука. Главная редакция ФМ литературы, 1984. $-288 \mathrm{c}$. 
3. Shabana, Ahmed A., 2010- Computational dynamics / Ahmed A. Shabana. - 3rd ed. p. cm.

4. Ткач М.М., Гуменний Д.О. Моделювання руху антропоморфного крокуючого апарата на довільній твердій поверхні // Адаптивні системи автоматичного управління. - 2012. - №21(41). C. $114-122$.

5. Ткач М.М., Гуменний Д.О. Керування рівновагою антропоморфного крокуючого апарата за інформацією про екстремуми на поверхні руху // стратегия качества в промышленности и образовании. - 2013. - Варна

6. D. Gumennuy, M. Tkach. A Hybrid Control Method fot Stabilizing of Walking Robot on Irregular Surface Using Plantar Pressure Sensor//ECCOMAS Thematic Conference on Multibody Dynamics. 2013

7. Кисленко Ю.И. Тактильное очувствление шагающего робота. Техническая кибернетика № 6 УДК 62-50 1991 г.

8. Белецкий В.В. Двуногая ходьба: иодельные задачи динамики и управления. - М.:Наука. Главная редакция фризикоматематической литературы, 1984. - 288 с.

9. Chow C.K., Jackobson D.H., Postural Stability of Human Locomotion. Mathem. Biosci., 15 (1972).

10. Hill J.C., A Dynamics Model of the Human Postural Control System, Final Rep., School of Eng. Okaland, Univ. Rochester, Michigan, 1970.

11. Muybridge E., Animals in Motion, Dover Publ., New York, 1957

Отримано 21.03.2014 p. 